\title{
BIBLIÓFILAS, SIM! BREVES APONTAMENTOS SOBRE DUAS BIBLIOTECAS DE MULHERES BRASILEIRAS
}

\section{WOMEN COLLECTORS, YES! BRIEF NOTES ON TWO BRAZILIAN WOMIEN'S LIBRARIES}

Women Collectors, yes! Brief notes on two Brazilian Women's Libraries

Fabiano Cataldo Azevedo ${ }^{53}$

Elisangela Silva da Costa ${ }^{54}$

Kátia Leal Silva ${ }^{55}$

\footnotetext{
${ }^{53}$ Doutor em História (UERJ), Mestre em Memória Social (UNIRIO) e Bacharel em (UNIRIO). Professor Adjunto da Universidade Federal do Estado do Rio de Janeiro (UNIRIO). Email: fabiano.azevedo@unirio.br

${ }^{54}$ Doutoranda em História Social da Amazônia (UFPA), Mestre em Educação (UFPA). Bibliotecária da Seção de Obras Raras da Biblioteca Central da UFPA. Email: lisa@ufpa.br

${ }^{55}$ Bacharela em Biblioteconomia (UNIRIO), Bibliotecária do Colégio Marista São José - Unidade Barra Da Tijuca RJ. Email: kl.silva50@gmail.com
} 


\title{
Resumo
}

O colecionismo de livros por mulheres é a tônica deste artigo. Para tanto, foram feitas reflexões à luz de autores, como: Quentin-Bauchart (1886), Roberts (1895), Cim (1901), Darnton (1992), Courceles e Júlian (1999), Azevedo (2010), Palma Peña (2013), Bessone (2014), Hastings (2014) e Melo (2018). Do ponto de vista metodológico, foi realizado o estudo de dois casos: a bibliófila paraense Annunciada Chaves e a bibliófila gaúcha Salete Maccalóz, cujas trajetórias serão analisadas segundo os seguintes aspectos: do nascimento e morte; formação; inserção social e interesse pelos livros até o destino de suas bibliotecas; características de suas bibliotecas, ilustrando peculiaridades bibliofílicas. Para conclusão, nosso objetivo é modesto, qual seja, contribuir para expandir de algum modo a temática no sentido de a não causar tanto estranhamento, a termos como: "Bibliófila"; "Biblioteca de Mulher"; "Mulheres e Colecionismo" etc.

Palavras-chave: Bibliofilia feminina. Colecionismo. Patrimônio bibliográfico.

\begin{abstract}
The collection of books by women is the keynote of this article. For this, reflections were made in the light of authors, such as: Quentin-Bauchart (1886), Roberts (1895), Cim (1901), Darnton (1992), Courceles and Júlian (1999), Azevedo (2010), Palma Peña (2013), Bessone (2014), Hastings (2014) and Melo (2018). From a methodological point of view, the study of two cases was carried out: the Paraense bibliophile Annunciada Chaves and the Gaúcha bibliographer Salete Maccalóz, whose trajectories will be analyzed according to the following aspects: from birth and death, training, social insertion and interest in books until the destination of their libraries, characteristics of their libraries, illustrating the bibliographic characteristics. In conclusion, our objective is modest, that is, to contribute to expand the theme in some way so as not to cause such strangeness as words: "Bibliophile"; "Women's Library"; "Women and Collecting” etc.
\end{abstract}

Keywords: Women Collectors. Bibliophile. Documentary heritage. 


\section{INTRODUÇÃO}

"My library is an archive of longings." (Sontag, 2012: 45)

Este artigo pretende tecer algumas considerações sobre as bibliotecas de duas mulheres nascidas no Brasil na primeira metade do século $\mathrm{XX}$, em regiões diametralmente opostas, ou seja: uma no Norte (em Belém-PA), e a outra no Sul (em Soledade-RS). Maria Annunciada Ramos Chaves (1915-2006) e Salete Maria Polita Maccalóz (1946-2017) possuíam muitas similaridades, a começar pela formação, pois eram advogadas e intelectuais. Ambas formaram suas bibliotecas como verdadeiras bibliófilas, uma vez que além dos livros de ofício, colecionaram outros com vieses de fruição e prazer, como veremos adiante. Não deixaram herdeiros, por isso seus livros foram doados e institucionalizados.

As reflexões teóricas que faremos orbitam unicamente em torno do nosso objeto de estudo, pois o interesse pelo tema foi provocado pelo conhecimento da história dessas duas bibliófilas. Elas nos motivaram e continuam a motivar o mergulho nesse tema.

Nesta pesquisa, partiu-se do princípio de que a bibliofilia é como um tipo de colecionismo, tal como argumenta e assevera, de forma muito clara, a 
pesquisadora Kelly Melo (2011; 2018). Sim, colecionar livros, não necessariamente livros raros e luxuosos, simplesmente livros para o deleite, como muitos professores acadêmicos fazem ao longo de suas carreiras.

Essa observação endossa uma das premissas deste artigo, de que ainda hoje há quem diga que bibliofilia não está relacionada a conhecer livros, mas simplesmente ao ato de colecionar determinados tipos de livros. Seja lá qual for o tipo de livros, de aqueles que custam centavos ou milhões, tudo isto são características do ato de colecionar livros.

É preciso ainda esclarecer que não pretendemos tratar da história da leitura, mulheres leitoras, pois fugiria do nosso intento aqui. Se, na área de estudos de Gênero, a análise sobre bibliotecas de mulheres, ou melhor, o reconhecimento de sua importância, já é algo introjetado, perguntamos como o assunto vem sendo tratado dentro da História do Livro? Uma simples busca em bases de dados brasileiras revelou um índice de revocação zero ${ }^{56}$ para os termos "Bibliófila"; "Biblioteca de Mulher"; "Bibliofilia feminina". Por que isto?

Há exceções, felizmente, em dois trabalhos: o de Reifschneider (2011), intitulado A Bibliofilia no Brasil, pois nele cita as professoras Ana Maria Camargo (São Paulo) e Regina Fiúza (Fortaleza) como Bibliófilas. Além dele, na dissertação "Rubens Borba de Moraes e José Mindlin: bibliofilia como patrimônio informacional", Adelma Araújo (2017), ao falar do casal Mindlin, diz que: não há registros da bibliofilia da senhora Guita, e faz duas perguntas

\footnotetext{
${ }^{56}$ Em 28 de julho de 2018 as pesquisadoras Luciana Maria Napoleone e Ivani Di Grazia Costa apresentaram, na cidade de São Paulo, a palestra "Olhares que constroem coleções: reflexões sobre algumas bibliotecas particulares paulistas". Nesse contexto, analisaram à luz da história social, a prática bibliofílica de Emma Gordon Klabin (https://emaklabin.org.br/). Sobre o citado evento, confere: http://www.crb8.org.br/palestra-olhares-que-constroem-colecoes-reflexoes-sobre-algumas-bibliotecasparticulares-paulistas/
} 
intrigantes: primeiro, se "Existirão mulheres no futuro da história da bibliofilia?” e se “Serão pesquisadas bibliófilas?” (Araújo, 2017).

Afirmarmos que não há só futuro, mas uma longa história de bibliófilas que ora são apagadas, ora são inferiorizadas, ou subvalorizadas. E sim, são e deverão continuar a ser pesquisadas, como é o caso deste artigo.

Ao se estudar a apropriação do livro pela mulher, verifica-se que os poucos trabalhos que existem abordam o período até o século XIX, e com enfoque em bibliotecas em casas religiosas, nas quais a biblioteca é comunitária e não de uma pessoa em específico (Courcelles e Julian, 1999). Outro tipo de biblioteca também muito explorado corresponde àquelas que pertenceram às mulheres de casas reais, da corte e da aristocracia (Anastácio, 2014; Souza, 2017).

E as mulheres dos séculos XIX, XX e até do XXI? Onde estão os estudos sobre elas? Existem e seguem sendo produzidos, mas, afirmamos, sem ganhar o mesmo destaque - seja na ciência, seja na imprensa - tanto como as bibliotecas de homens. Em vários casos, seria necessária uma análise de discurso pois, o que percebemos, empiricamente, é ela estar associada à “singela", em oposição à qualidade científica, por exemplo. E o que pode ser ainda pior, quando são livros didáticos, acumulados por anos de ofício de uma professora, por exemplo, podem, inclusive, não serem percebidos como patrimônio bibliográfico. Infelizmente, paira a ideia do patrimônio bibliográfico associado ao que é raro, e este ao que é antigo, e, com frequência, os livros didáticos ficam de fora desse grupo. Todavia, estamos a falar aqui, também de conhecimento científico, de cultura escrita.

No caso de biblioteca particular pessoal de mulheres, parece-nos que faltam trabalhos que enfatizem que naqueles livros estão a trajetória de uma pesquisadora por exemplo. Ali estão o DNA de toda uma rede de trabalho que 
desenvolveram durante o período de atividade profissional, como a pesquisadora Francisca Maciel (2001) fez na tese na qual deslinda a biblioteca pessoal atrás do método da professora Lúcia Casasanta, mas sem, contudo, caracterizá-la como bibliófila.

Em linhas gerais, pretende-se estabelecer algumas reflexões sobre o processo de institucionalização de coleções que configura a transmissão de um bem privado para o público. Para fins de delimitações conceituais, consideramos que estamos no terreno das Bibliotecas Particulares Pessoais.

Ao ser institucionalizada, deveria ser irrelevante, num primeiro momento, saber se no conjunto de livros há obras raras ou não. Diante de todas essas características, as perguntas mais importantes poderiam ser: qual a relação identitária dessa coleção com a história da instituição? com a história de uma área do conhecimento? com a história de uma cidade? etc.

Nesta conjuntura, considera-se que essas bibliotecas ${ }^{57}$ são Patrimônio Bibliográfico e Documental - conceito que neste artigo será baseado em Palma Peña (2011; 2013) e Jaramillo (2014).

Essas coleções quando institucionalizadas, ou seja, quando passam do privado para o público, por sua natureza, são identificadas como "Coleções Especiais", ou seja, um conjunto de livros reunidos artificialmente pela relação identitária em comum, por características individuais, mas sobretudo

\footnotetext{
${ }^{57}$ Sobre esse tipo de coleção, Portugal possui uma legislação muito precisa. Ver: Portugal. Procuradoria Geral Distrital de Lisboa (2001). Lei n. 107/2001, de 08 de setembro. Lei de Bases do Património Cultural. Disponível em: http://www.pgdlisboa.pt/leis/lei_mostra_estrutura.php?tabela=leis\&artigo_id=\&nid=844\&i nversao=\&tabela=leis\&so_miolo. Acesso em: 02.04.2020.
} 
por possuir correspondência patrimonial com o local que as recebem. Elas são mantidas separadas também por preservação e segurança. A atribuição de raridade dos itens deve considerar critérios institucionais e identitários.

Tais coleções, como a maioria das bibliotecas, são formadas por escolhas pautadas em gostos pessoais, influências políticas que podem se configurar em um reflexo, ou até mesmo um simulacro, dos anos em que a coleção foi desenvolvida. Por essa razão, também compreendemos a Biblioteca Particular Pessoal como um lugar de memória, como assim a considera Namer (1937), ou seja, não pelo espaço, mas pelo conteúdo. E esta possui uma relação absolutamente sinérgica com o espaço que ocupa, ou seja, a casa do proprietário e com o próprio, uma triangulação como define Assmann (2011).

Assim como acontece em um arquivo privado onde se faz memória de si, e se forja o que se pretende preservar, acreditamos que o mesmo ocorre na Biblioteca Particular Pessoal, por isso não podemos aceitar placidamente a ideia de que essas bibliotecas representem o "genoma intelectual" como afirma Zaid (2004). Claro que para compreender uma Biblioteca Particular Pessoal é preciso conhecer um pouco da biografia do antigo dono (Cândido, 1989), mas isso não resulta em um deslindar transparente do perfil de suas bibliotecas, mas traços de uma trajetória.

Além desta introdução, há outras três partes que estão implicitamente divididas em movimentos que buscam endossar nossa abordagem. Primeiro, para fazer alguns breves apontamentos sobre a figura da mulher bibliófila, selecionamos a partir de Le Femmes et les livres, publicado por Albert Cim (1919) alguns livros dos séculos XVII ao XIX que, diretamente ou indiretamente, citaram ou escreveram especificamente sobre o assunto, sem, contudo, almejar revisão historiográfica. 
Na segunda seção, adentraremos nos traços biográficos das duas mulheres que motivaram este trabalho, privilegiaremos o contexto do nascimento e morte, formação, inserção social e interesse pelos livros, até o destino de suas bibliotecas. Por fim, pretende-se indicar algumas características de suas bibliotecas, ilustrando as peculiaridades bibliofílicas. Notar-se-á que existem mais detalhes acerca da biblioteca de Annunciada, isto se dá porque sua doação aconteceu há mais tempo, além de ter sido objeto de conferências anteriores e de uma investigação para doutoramento. Para conclusão, nosso objetivo é modesto, qual seja, contribuir para expandir de algum modo a temática, no sentido de não causar tanto estranhamento a palavras, como: "Bibliófila"; "Biblioteca de Mulher"; "Mulheres e Colecionismo" etc.

\section{BIBLIÓFILAS... E POR QUE NÃO?}

Essa seção é apenas um interregno entre a introdução e ponto central deste artigo, ou seja, não há intenção de uma ampla revisão historiográfica sobre o tema.

Diaconoff (2005) comenta que a relação da mulher com o livro, não obstante no período ter sido intensa e comprovadamente imbricada, foi silenciada e pouco explorada. O espírito da mulher não era próprio para o conhecimento, ou como dizia um ditado muito comum no Brasil do século XIX, "à mulher, basta saber ler para compreender o catecismo".

Em muitos casos, a ideia do "espírito fraco" era associada a algo ainda pior, ou seja, ela teria uma mente fraca, facilmente influenciável. Em ler demais, jazia o "perigo" dela se tornar uma intelectual, ou "pior", se tornar uma Bovary. Mas já se falou muito sobre isto, logo nada teríamos a contribuir ou acrescentar. Por isso, nosso foco aqui é a mulher colecionadora de livros, bibliófila, no século XX. 
Por mais incrível que possa parecer, pelo menos até o século passado, as várias apropriações das mulheres com o livro era quase um anátema. Mulheres escritoras, leitoras e donas de bibliotecas? Inúmeras são as pesquisas que já estudaram autoras que tiveram que assinar sob pseudônimos, por exemplo.

Em Les femmes bibliophiles de France (XVIe, XVIIe \& XVIIIe siècles) escrito por Ernest Quentin-Bauchart e publicado em 1886, a introdução deixa a ideia de que é uma discussão que já vinha sendo feita por um tempo no país.

"Il nous a donc paru qu'une étude bibliographique sur les femmes qui, à des titres divers, ont mérité de prende place à côté des grands amateurs d'autrefois, aurait quelque chance d'etre favorablement accueillie, et nous n`avons riem négligé pour qu'elle fut aussi compléte que possible, malgré les difficultés que devait nécessirement rencontre un travail de cette nature" (Quentin-Bauchart, 1886: 2).

Ele afirma que, apesar de poder parecer impreciso, considera que o título escolhido para o livro é o que melhor representa suas intenções. Sem fazer distinção entre os gêneros, pondera que existem dois tipos de colecionadores um que "considerèrent le livre comme um objet de mode et de luxe, ou comme une sorte de valeur de bourse [...]". Todavia, há outros que "le recherchent pour ce qu'il contient, pour as rarité et as belle condition matérielle de texte et de relieure" (Quentin-Bauchart, 1886: 2). Também sem estabelecer diferença entre homens e mulheres diz que houve casos nos quais, mesmo com valores altíssimos, "il y avait quelques grands seigneurs qui possédaient 
des livres, parce qu'il était de bon ton d'en avoir, mais qui ne les regardaient et ne les ouvraient jamais" (Quentin-Bauchart, 1886: 3).

Com essa linha de raciocínio, escreve um livro que traz traços biográficos relacionados à bibliofilia e influência social de vinte e quatro mulheres da nobreza francesa. Em alguns momentos, exorta a contribuição que algumas coleções dão aos estudiosos da história da encadernação na França e menciona casos onde a biblioteca teria sido fundamental para as ações políticas de algumas dessas mulheres.

O tema mulheres bibliófilas foi objeto de interesse da pintora inglesa Norma Labouchere, que em 1895 publicou em Londres Ladies's book-plates: an illustrated handbook for collectors and book-lovers. Chama-se a atenção de que não se trata de um livro sobre ex libris com figuras femininas, mas um livro sobre ex libris que algumas mulheres usaram em suas bibliotecas. É notório o fato de ser escrito e assinado por uma mulher, diferentemente de outros que vieram antes e depois, escritos por homens.

Ao descrever suas motivações e fazer uma espécie de revisão de literatura observa que a Inglaterra vinha se dedicando muito aos estudos sobre ex libris, mas nota que "women's book-plates may not have been considered to offer a fertile field; yet surely the subject is sufficiently rich in material for a monograph" (Labouchere, 1895: viii).

Os capítulos do livro são ainda mais instigantes, pois, dentre outros, há um sobre mulheres bibliófilas (women bibliophiles), no qual ela comenta as bibliotecas de Cleópatra e de Santa Brígida. Neste capítulo especificamente, Labouchere citará alguns exemplos na França; e, em ambos os casos é curioso notar que em algumas passagens, além de rainhas, princesas e abadessas haviam outras senhoras da aristocracia que conseguiram ter sua própria 
biblioteca. Por fim, há um outro capítulo todo dedicado à heráldica e às frases usadas nos ex-libris de bibliotecas de mulheres.

Hastings (2014) sugere que colecionar livros requeria que a mulher tivesse recebido uma educação refinada, por isso, muitas bibliófilas até o final do século XIX eram ligadas à nobreza e à alta aristocracia. No entanto, ainda assim, "these ladies were often dismissed as serious book collectors; they were accused of collecting because it was fashionable, not from a true love of books". Ou seja, era um hobby de mulheres ricas ${ }^{58}$.

No livro The book-hunter in London, publicado em 1895 por W. Robert, há um capítulo chamado Women as a book-collectors. Vemos que a presença deste capítulo, mesmo que, à luz da época, repleto de comentários misóginos, é um importante indicativo do espaço que a mulher ocupava neste cenário, sendo respeitada e aceita ou não.

Curiosamente, começa o texto afirmando que considerava uma contradição o fato das mulheres inglesas serem formalmente reconhecidas como maiores e melhores leitoras do que os homens; mas suas práticas como colecionadoras e compradoras de livros eram quase desconhecidas. Por outro lado, na França o assunto da femmes bibliophilie ganhava notoriedade com vários livros publicados. No entanto, para ele, a "analysis of their book-possessions, however, leads one to the conclusion that with them their sumptuously-bound volumes partake more of the nature of bijouterie than anything else" (Roberts, 1895: 259).

\footnotetext{
${ }^{58}$ Não deixam de ser curiosos os comentários de Rubens Borba de Moraes sobre a imagem que, no século XX, muitos têm dos Bibliófilos. Entre os homens, ele também tenta diferenciar o Bibliófilo que para ele é quem conhece livro integralmente, sabe o que está fazendo; do Colecionador, que ele diz ser quase que um mero acumulador de livros (Moraes, 1976).
} 
Nessa linha, ou seja, na construção de uma narrativa menos negativa e naturalizada acerca da formação de bibliotecas por mulheres, em 1901, Albert Cim publica em Paris, o Le femmes et les livres, cuja motivação para escrevêlo é declarada no início:

Après quelques pages consacrées aux femmes ennemies des livres, "bibliophobes", selon le terme employé par George Sand, je passe em revue, autant que possible dans l'ordre chronologique, les nombreuses amies des livres ou bibliophiles, non seulemente celles qui ont rassemblé d'importantes ou luxueuses collections, mais celles aussi qui ont laissé témoigne de leur goût pour la lecture et l'étude (Cim, 1901: 2).

Ou seja, sua ponderação soa crítica àqueles que consideram as mulheres como inimigas dos livros ou meras acumuladoras. A seguir, Cim (1901) faz uma revisão de literatura que arrola pontos de vistas negativos sobre a relação mulher e livro, sempre em tom muito crítico.

Historicamente, presume-se que a relação que a sociedade tem feito entre a mulher e livro por séculos tem carregado uma pecha muito nefasta. Hastings (2014) acredita que remonta a Bury, que em Philobiblon, publicado em 1344, falou da mulher através de um livro como personagem da seguinte maneira:

"(...) by that biped beast whose cohabitation with the clergy was forbidden of old, from which we have always taught our nurslings to flee more than from the asp and the cockatrice; wherefore she, always jealous of the love of us, and never to be appeased, at length seeing us in some corner protected only by the web of some dead spider, with a frown abuses and reviles us with bitter words, declaring us alone of all the furniture in the house to be unnecessary, and 
complaining that we are useless for any household purpose, and advises that we should speedily be converted into rich caps, sendal and silk and twice-dyed purple, robes and furs, wool and linen: $[\ldots]$.

$\mathrm{Na}$ literatura consultada notamos que no século XIX o "termo técnico" mais usado passou a ser femme bibliophiles, que, em raros casos, só era considerada como tal dependendo do seu histórico no contexto da cultura política do momento. Caso contrário, o seu hábito era considerado algo frívolo, dizia-se que colecionavam livros pela beleza das encadernações, como um objeto qualquer, e não tinham nenhum apreço pela leitura em si (Roberts, 1895).

Ainda que pareça estar elogiando a bibliofilia das mulheres inglesas, para ele "for all practical purposes, Queen Elizabeth may be regarded as the first distinguished femme bibliophile" (Roberts, 1895: 262), isto porque considera que com ela os livros eram colecionados muito mais pelo conteúdo. Sem detalhar a razão, afirma que a sua geração "has produced two of the most distinguished femmes bibliophiles which has ever known. The earlier collector, Miss Richardson Currer (1785-1861) [...] was the owner of an exceendingly rich library books" (Roberts, 1895, p. 270).

Entre a primeira e segunda mulher a merecer dele o título de femme bibliophile, ele elenca outras tantas, mas, novamente, os critérios não ficam claros. Mrs. John Rylands parece ter recebido destaque porque em 1889 "formed the plan of erecting in Manchester a memorial to her late husband, which should embody on main purpose of his life [...]" (Roberts, 1895, p. 272). Dentre seus objetivos, estava "to make the highest literature accessible to the people was with him a cherished aim, and it was accordingly resolved by his widow that the memorial should be in the form of a library" (Roberts, 
1895, p. 272). Para levar a cabo o empreendimento, contratou quatro intelectuais [homens] renomados para seleção e compra dos livros.

Um ponto em comum entre todos os casos: não eram as mulheres a lidar com livreiros, a escolher, selecionar, a negociar. Gelber (1999: 103) dizia que: "the only women collectors taken seriously by men were those who collected on men's terms". Seria esse o jeito feminino de bibliofilia?

Roberts considerava as femme bibliophile como muito desconhecidas e acreditava que: "the New Woman may develop into a genuine book-lover; it is certain that the old one will not" (Roberts, 1895: 273), pois ele acredita que "mulher de antigamente" se enquadrava num ditado chinês que dizia que as mulheres não tinham alma, e que por isso, não poderiam fazer parte de um universo.

Outro exemplo funesto é citado por Gelber (1999: 103):

"Book collectors in particular have perceived women as the enemy, none more so than the poet Eugene Field who in 1896 described heaven as a place full of books but devoid of women. Women, he said, want food and love, but male collectors spend both their money and their emotions on books. Bibliophile Vicent Starrett conceded that book collecting was not a rational expenditure of funds and that 'the wives are eminently pratical and they instinctively recognize the futility of the collecting habit, save as it has to do with such practical items as silk patches and bits of ribbon."

Em 1937, Anne Lyon Haight publicou o livro As mulheres são os inimigos naturais dos livros? justamente para refutar essa ideia, apresentou a trajetória de várias bibliófilas notáveis. Para ela, no entanto, infelizmente, os trabalhos 
sobre mulheres colecionadoras de livros são superados em número por muitos escritores que chamam as mulheres de inimigas dos livros.

No Brasil, a imagem da mulher, no universo do livro, ou mais especificamente em temas que orbitam as Bibliotecas Particulares, como Bibliofilia e Colecionismo, é quase sempre anedótica. Clássicas frases, como: "Viúvas, alegria do sebo" ou ainda "O féretro sai por uma porta e a biblioteca pela outra" (Cavedon, 2007: 345). São proferidas sempre atribuindo a figura feminina como bibliopata, ou seja, inimiga das bibliotecas. Assim, ela assume contornos tão negativos que entra no rol das principais causas de dispersão de bibliotecas particulares, junto com o fogo e o roubo.

Em textos que beiram a contos, a biblioteca particular de um bibliófilo é a personificação de uma amante com a qual a mulher teve que rivalizar praticamente ao longo de toda a vida. Afinal, nem todos foram tão sábios quanto Rui Barbosa e José Mindlin, que tornaram suas esposas sócias na formação e gestão, e sobretudo na conservação de suas bibliotecas. A mulher como "cuidadora" de livros recaí na figura caricata da bibliotecária, mas não como dona e formadora de uma coleção pessoal.

Assim, por essas breves achegas podemos inferir que nos últimos séculos a imagem de uma mulher com biblioteca nem sempre foi positiva e parece que o terreno da Bibliofilia não é algo para o gênero. A seguir, apresentaremos duas personagens do Brasil que podem se somar a outros exemplos de mulheres que colecionaram livros como instrumento aos seus ofícios, mas também para o lazer e prazer pessoal.

\section{DO NORTE AO SUL: DUAS BIBLIÓFILAS BRASILEIRAS DO SÉCULO XX}


Em 16 de dezembro de 1915 nascia na cidade de Belém do Pará, região Norte do Brasil, Maria Annunciada Ramos Chaves. Filha primogênita, do contador Joaquim Chaves e da dona de casa Maria D'Ascensão Ramos Chaves, também paraenses, que além de Annunciada tiveram mais três filhas: Paula, Lourdes e Júlia (Sarges, 2016).

A qualidade de sua formação não fugiu à regra das demais moças nascidas em famílias abastadas naquele início de século. Recebeu, em casa, os primeiros elementos de educação de Amância Pantoja Borralho, professora do Grupo Escolar Rui Barbosa. A seguir, ingressou no renomado Instituto Gentil Bittencourt (atual Colégio Gentil Bittencourt), instituição que inicialmente era um orfanato, o chamado Colégio Nossa Senhora do Amparo; mas gradativamente se tornaria uma referência na qualidade do ensino. Posteriormente, vai para o Colégio Moderno para dar continuidade aos seus estudos; mesma instituição na qual, anos mais tarde, ela viria a lecionar, ser coordenadora pedagógica e sócio proprietária (Rego, 2002).

Além de decidir prosseguir os estudos, escolhe um curso que tradicionalmente ainda não era considerado "um espaço para mulheres". Destarte, no ano de 1932, ingressa na Faculdade Livre de Direito do Pará, na qual durante todo o curso, teve um desempenho acadêmico irrepreensível. Ainda assim, em função de uma norma aplicada apenas às estudantes para que a matrícula fosse renovada, todo semestre devia apresentar uma carta de anuência paterna.

Em 1934, com 19 anos, no terceiro período da graduação, recebe o convite do Professor Osvaldo Serra para lecionar a disciplina de História do Brasil no Colégio Moderno, passando a cumprir dupla jornada. Este fato gerou uma situação que evidencia um pouco o próprio caráter de Annunciada, seu pai chegou ao extremo de tentar impedi-la. Todavia, de posse de sua herança, já partilhada por ele, comprou parte do colégio (Damaso, 1997). Começava 
assim uma carreira, como professora de História, paralela à de advogada, o que lhe traria grande projeção e a qual se dedicaria até a década de 1952.

Em 17 de janeiro de 1947, Annunciada foi uma das fundadoras da Faculdade de Filosofia, Ciências e Letras (atual Instituto de Filosofia e Ciências Humanas/Universidade Federal do Pará), razão pela qual credita-se a ela contribuição para a diversificação do ensino superior no estado (Beckmann, 2006).

Dentre outras instituições, também esteve entre os fundadores da Sociedade Paraense de Educação e do Conselho Estadual de Cultura onde, posteriormente, foi presidente por quatorze anos (1972-1986). O que corroborou muito para consolidar seu forte relacionamento com a educação e cultura.

Em concomitância com o exercício da advocacia e da carreira acadêmica, Annunciada também se destacaria na seara administrativa, tendo sido a primeira Secretária da Caixa de Assistência dos Advogados do Pará, bem como ocupou o cargo de Sub-Reitoria de Extensão e Assuntos Estudantis da Universidade Federal do Pará, exercendo este cargo por oito anos, atravessando os mandatos dos Reitores Aloysio Chaves (gestão 1969-1973) e Clóvis Malcher (gestão 1973-1977).

Alcançou respeito e reconhecimento intelectual em várias esferas no contexto paraense. Pertenceu ao Instituto Histórico e Geográfico do Pará, onde ocupou a cadeira de n. 65. De 1975 a 2006, fez parte da Academia Paraense de Letras, em que ocupou a cadeira de n. 22 (Beckmann, 2006). 
Incansável, no início dos anos 2000, já com 85 anos, Annunciada passou a se dedicar mais à editoração de periódicos científicos, tais como: a Revista de Cultura do Pará e a Revista da Academia Paraense de Letras.

Por essa época, gradativamente, foi se retirando do cenário intelectual paraense e após quase setenta anos de atividade profissional dedicados a todas as esferas da educação e cultura, faleceu em 16 de agosto de 2006, no Hospital Oncológico Ophir Loyola em Belém do Pará, aos 90 anos.

$\mathrm{Na}$ década em que Annunciada Chaves ajudava a fundar a Faculdade de Ciências Econômicas, Contábeis e Atuariais; em 31 de outubro de 1946, na cidade de Soledade, Estado do Rio Grande do Sul, nascia Salete Maria Polita Maccalóz, filha de Alfredo Maccalóz e Zita Polita Maccalóz.

Salete Maccalóz, em 1962, completou o primeiro grau no Ginásio São José. Quatro anos depois, se forma em professora pela Escola Normal Santíssima Trindade, na cidade de Cruz Alta, RS. Em 1972, terminou o curso de Direito na Faculdade de Ciências Jurídicas e Sociais da Pontifícia Universidade Católica do Rio Grande do Sul (PUC-RS). Cinco anos depois, em 1978, inicia sua profícua carreira de advogada.

Posteriormente, cursou o Mestrado em Ciências Jurídicas e Sociais, pela Pontifícia Universidade Católica do Rio de Janeiro (PUC-RJ), logrando seu título de Mestre em maio de 1981. Cursou o Doutorado em Comunicação e Cultura pela Universidade Federal do Rio de Janeiro (UFRJ), e defendeu sua tese em 24 de maio de 2000.

Maccalóz atuou profissionalmente com Advocacia Liberal a partir do ano de 1973, na cidade de Porto Alegre, capital do Estado do Rio Grande do Sul. Na Ordem dos Advogados do Brasil, seção Rio de Janeiro, foi nomeada 
Advogada Instrutora da Comissão de Ética e Disciplina para o biênio 19811982, e, posteriormente, Advogada Delegada da Comissão de Direitos Humanos e Assistência, atuando também como Advogada Liberal na Cidade do Rio de Janeiro até o ano de 1988, ainda acumulando as funções de Advogada Concursada da Comissão de Valores Mobiliários (CVM) de 1978 até 1988, e membro efetivo do Instituto dos Advogados do Brasil desde o ano de 1998.

Em 26 de fevereiro de 1988, tomou posse como Juíza Federal do Tribunal Federal de Recursos da $1^{\mathrm{a}}$ Região em Brasília - Distrito Federal. Atendeu a várias convocações de auxílio às $1^{\mathrm{a}}, 2^{\mathrm{a}}$ e $5^{\mathrm{a}}$ turmas entre 1998 e 2002, e foi nomeada por Decreto, em 16 de dezembro de 2008, como Juíza do Tribunal Federal da $2^{\mathrm{a}}$ Região. Foi Presidente da $7^{\mathrm{a}}$ Turma deste mesmo Tribunal em 2009, Presidente da $3^{\text {a }}$ Turma do Tribunal Regional Federal (TRF2) no período de 2010/2011, bem como Corregedora Regional da Justiça Federal da $2^{\text {a }}$ Região entre 2013 e 2015, além de compor o Conselho de Administração do TRF2 no mesmo período.

Em 7 de dezembro de 2017, na inauguração da Estante Salete Maccalóz composta pelo acervo doado à biblioteca do Centro Cultural Justiça Federal, Saulo Maccalóz, seu sobrinho, relata verbalmente características sobre a "pessoa e mulher " Salete Maccalóz, que sempre demonstrou amar seus familiares, especialmente seus sobrinhos, revela que quando Salete visitava sua cidade natal em férias, capinava junto com eles o terreno baldio de frente para casa, para que pudesse depois jogar com eles partidas de futebol, confidenciou que por admiração resolveu cursar Direito assim como a tia e , ao se formar advogado, ganhou como presente de formatura a coleção do "Tratado de Direito Privado", obra considerada como a mais importante do jurista Pontes de Miranda, imortal da Academia Brasileira de Letras, fato interessante de comentar pois "quem ama livros, gosta de presentear com livros (Brasil, 2017). 
Como a colega paraense, também exerceu carreira de docente. Em sua trajetória, foi Professora Adjunta/Doutora concursada da Faculdade Nacional de Direito da Universidade Federal do Rio de Janeiro (UFRJ), concursada em 1994 e nomeada em 2007 para as cadeiras de Direito de Trabalho I, Direito do Trabalho II, Processo do Trabalho e Previdência Social; Professora Adjunta/Doutora concursada da Universidade Estadual do Rio de Janeiro (UERJ) com posse em agosto de 1997 até março de 2007; Professora e Orientadora de Direito do Trabalho, Direito Previdenciário e Direito Sindical pela Pontifícia Universidade Católica do Rio de Janeiro (PUC-RJ) e, ainda nesta instituição, Professora de Direito do Trabalho do Instituto de Aperfeiçoamento Gerencial-Recursos Humanos, de 1982 até 2000. Teve 37 de trabalhos publicados entre livros, artigos, pareceres e ensaios.

Além disso, ministrou cursos em escolas de pós-graduação de strictu sensu entre 2000 e 2002, no Mestrado de Medicina do Trabalho na UERJ, bem como, em vinte cursos lato sensu, de 1978 até 2004, em diferentes áreas do Direito. Exerceu significativa participação em entidades de classe desde os seus primeiros anos de atuação profissional, incluindo nove eventos internacionais, e obteve aprovação em 11 concursos públicos. Faleceu na cidade do Rio de Janeiro, em 2 de fevereiro de 2017, com 71 anos.

Na ocasião do passamento, Amália E, Fisher, coordenadora geral do Fundo ELAS, fez uma declaração publicada em meio eletrônico na página da instituição, que constitui uma significativa declaração acerca do perfil de Maccalóz:

"[ela] era uma feminista muito reconhecida por seus importantes posicionamentos dentro da área jurídica no que se refere aos direitos humanos. Ela foi uma das maiores entusiastas quando falei da ideia de criar um fundo para apoiar o movimento de mulheres, acreditava muito no 
potencial transformador das doações e do trabalho social por ter participado quando jovem do Movimento Bandeirante" (Fischer, 2017).

Neste panorama, percebemos alguns traços dessa mulher, forte, combativa, desejosa de um mundo mais justo, daí onde se compreende seu direcionamento dentro da profissão e, por consequência, seu gosto por leituras que tratavam do tema das relações humanas em sociedade.

Apesar dos estudos sobre as trajetórias de Annunciada Chaves e Salette Maccalóz ainda estarem em curso, o relato feito evidencia que ambas tiveram em vida notoriedade como intelectuais, com um histórico de formação exemplar. Como mostra Bessone (1999) ao estudar a bibliotecas de $\operatorname{advogados}^{59}$, estes por natureza do ofício cultivavam uma formação complementar que transcende a do Direito. A figura de um advogado, ainda nos dias atuais, é associada à alta cultura. Não poderia ser diferente com nossas duas personagens.

Como veremos a seguir, suas bibliotecas foram seus instrumentos auxiliares de trabalho e espaço de fruição e formação.

\section{DUAS BIBLIOTECAS DE MULHERES BRASILEIRAS}

Uma das maiores tragédias que pode acontecer a uma biblioteca particular pessoal é o seu esquartejamento consequente de uma dispersão (Freire, 1921, Azevedo \& Freire, 2018). Infelizmente, os casos são vários - e não vamos

\footnotetext{
${ }^{59}$ Ver também: Holborn, Guy. Lawyers and their libraries. In: Black, A. and Hoare, P. (eds.), The Cambridge history of libraries in Britain and Ireland. Cambridge, 2006, v. 3 (1850-2000), p. 453-469.
} 
ousar entrar nesse nicho. As bibliotecas de Annunciada Chaves e Maccalóz ganharam um bom destino, passando pelo movimento do privado para o público.

Com mais de 70 anos de carreira e com uma reputação de grande intelectual, era de se esperar que a biblioteca pessoal de Annunciada Chaves fosse muito alardeada na cidade de Belém - como em alguns casos acontece, ou seja, a fama da biblioteca é pari passu da notoriedade do dono.

Como acontece com outros bibliófilos, sua coleção teve origem ainda na infância e Annunciada costumava deixar os primeiros livros que ganhou em uma estante separada em destaque na sua biblioteca - outra característica de colecionadores, como comentou Bessone (2006) em citação posterior.

Seu rigor científico e acadêmico espelhava nas escolhas que fizera para sua própria biblioteca que fora formada também com livros que havia herdado das três irmãs e de seus pais. Além de compras, livros escritos e prefaciados por ela, e devido sua rede de sociabilidade e influência que exercia na cidade, recebia muitos livros oferecidos. Por isso, acredita-se que o acervo tenha chegado a 20.000 livros, os quais, a professora costumava emprestar ou permitir o acesso de alguns estudiosos.

Ela não se casou e nem teve filhos, e suas irmãs faleceram antes dela. Em 2012, seis anos depois de sua morte, dos 20.000 livros que compunham sua coleção, 3.535 títulos (em sua maioria do século XX) foram entregues em doação ao Memorial do Livro Moronguetá, e desses, no momento, 2.805 estão disponíveis pois já passaram por higienização e catalogação.

Annunciada Chaves se formou conforme um perfil de advogados estudado por Bessone (1999), ou seja, eram detentores de formação que ultrapassa o 
próprio Direito e faziam questão de alimentar sua cultura e saber. A Tabela 1 elucida essa característica, pois é possível verificar assuntos auxiliares ao seu exercício profissional na área jurídica e como Historiadora, dentre outros.

Tabela 1 - Assuntos mais lidos por Annunciada Chaves

\begin{tabular}{|c|c|}
\hline Literatura & 791 \\
\hline História & 539 \\
\hline Biografia & 289 \\
\hline Geografia & 186 \\
\hline Arte & 122 \\
\hline Educação & 110 \\
\hline Economia & 102 \\
\hline Religião & 90 \\
\hline Cultura & 70 \\
\hline Política & 69 \\
\hline Filosofia & 69 \\
\hline Sociologia & 64 \\
\hline Direito & 52 \\
\hline Linguagem & 51 \\
\hline Administração & 39 \\
\hline Antropologia & 33 \\
\hline Ciências Exatas & 27 \\
\hline Psicologia & 23 \\
\hline Ciências da Terra & 22 \\
\hline Ciências da saúde & 19 \\
\hline Ciências da Vida & 17 \\
\hline Ciências Naturais & 8 \\
\hline Arquitetura & 6 \\
\hline Serviço Social & 4 \\
\hline Ciência Militar & 3 \\
\hline TOTAL & 2.805 \\
\hline
\end{tabular}

fonte: os autores. 
Quanto ao idioma, a proprietária revelou ter uma vasta cultura linguística, posto que ela possuía livros nos seguintes idiomas: português ( $81 \%$ das obras), seguido por livros em francês (11\%); além de inglês e espanhol (4\%) cada. Embora em menor frequência, livros em alemão e italiano também são verificados.

As marcas de proveniência (Pearson, 1998, 2019; Campos, 2015) associadas ao método do paradigma indiciário desvelaram outras características importantes da biblioteca, como por exemplo, de que forma que alguns livros foram incorporados à coleção, fundamentalmente por compra e doações (esses com autógrafos e dedicatórias ${ }^{60}$ ). Cerca de $64 \%$ das obras foram compradas por ela, cerca de 3\% das obras foram herdadas de parentes e $33 \%$ foram a ela dedicados ou autografados como agradecimento pela viabilização da edição da obra; ou foram presentes de familiares, amigos ou alunos.

Foi identificado que Annunciada usava duas formas de registrar a posse de seus livros, por carimbo úmido (4\%), esses em mais de um tipo, e ex-libris manuscrito (94\%). Possuía o hábito de anotar a data em que adquiriu a obra ou, em alguns casos, o local e até a hora.

Em relação às marcas de leitura, não era adepta às marginálias no miolo do livro, optava por fazer anotações em papéis avulsos (uma espécie que consideramos como "marginália avulsa") e guardá-las nos livros cujas leituras tivesse feito. Annunciada também tinha o hábito de fazer notas no sumário e no final do livro, com isso, criava uma espécie de índice remissivo para autores ou assuntos que julgava ser importante.

\footnotetext{
${ }^{60}$ Pela proposta metodológica, sobre essa forma de marca de proveniência indica-se a dissertação intitulada As dedicatórias manuscritas: relações de poder, afeto e sociabilidade na biblioteca de Manuel Bandeira, escrita pela Professora Stefanie Freire, em 2013 no Mestrado em História da UNIRIO.
} 
Além das "marginálias avulsas" no interior dos livros, foi possível encontrar fotografias, cartões de visita, cartões postais, cartões de natal e marcadores de página e, principalmente, cartões com imagens de santos, reforçando a sua conduta religiosa e católica.

Por fim, vale citar outro tipo muito recorrente de marca de leitura, mas cada dia mais em desuso. Annunciada Chaves deixava apenso ou fixado nos livros artigos de jornais com textos que podiam fazer referência ao autor (biografia, crítica ou o necrológio) e/ou ao assunto do livro.

Quanto à Salete Maccalóz não se sabe ao certo quando começou a formação de sua biblioteca, contudo pelo perfil das obras que a compõe, estima-se que possa ter sido iniciada desde sua juventude, pois ela manteve parte de seu acervo em sua cidade natal, onde iniciou seus estudos. Alguns itens ficaram com seus familiares que ainda residem na cidade de Soledade, porém certamente, a maior parte de sua biblioteca particular foi formada na Cidade do Rio de Janeiro, onde passou a maior parte de sua vida pessoal e profissional.

A Desembargadora colecionava muitos livros da área do Direito, e ainda dentro de sua veia profissional, mas voltada também aos traços de sua personalidade forte, obras ligadas às Ciências Sociais, Antropologia, e outros títulos que abordam as relações humanas em sociedade, que amparam sua atuação como Desembargadora e Juíza. Seu perfil biográfico nos indica a sua preocupação por justiça social e pelas as pessoas menos favorecidas, bem como na defesa das causas importantes para uma sociedade mais equilibrada nas esferas culturais, sociais, econômicas e ambientais. Essa percepção ficou evidenciada nas pesquisas realizadas na Hemeroteca Digital da Fundação Biblioteca Nacional, onde encontramos notícias publicadas em periódicos sobre decisões, opiniões e ações da Juíza e Desembargadora que deixam explícitos seus ideais de justiça. 
A destinação dos livros da biblioteca de Salete Maccalóz teve dois movimentos: um em 2017, quando uma de suas irmãs distribuiu a coleção entre as bibliotecas de três instituições: a da Faculdade de Direito da Universidade Federal do Rio de Janeiro, a do Tribunal Regional Federal $2^{\mathrm{a}}$ Região (TRF2) e a do Centro Cultural Justiça Federal (CCJF), todas na cidade do Rio de Janeiro. Os livros doados versavam sobre: Direito, Letras, Artes e outros assuntos associados ao lazer, como cinema, por exemplo.

Em 2019, acontece um segundo movimento, o conjunto de livros que estava na Biblioteca do TRF2 foi incorporado à Coleção Especial Salete Maccáloz, que já havia sido criada na Biblioteca do CCJF. Na mesma ocasião, a biblioteca recebeu da família da colecionadora 7.000 exemplares de histórias em quadrinhos, que eram mantidos em Soledade-RS.

A Coleção Especial Salelte Maccáloz - que ainda está em tratamento técnico dado suas especificidades - foi o primeiro acervo bibliográfico formado por uma mulher a fazer parte da Biblioteca do CCJF, onde já haviam duas outras doadas por famosos juristas na cidade.

Maccalóz gostava muito de viajar e conhecer lugares mundo afora, aventureira nata que não por descuido, esqueceu dentro de um guia de turismo sobre a Europa um bilhete do metrô de Paris. Nossa ilustre bibliófila colecionou mais que livros, adquiriu mais de 7.000 exemplares de histórias em quadrinho (como Flash Gordon, por exemplo), juntou mais de 1.000 cartões postais de suas viagens. Sua curiosidade sobre as pessoas revelou as razões de possuir em seu acervo algumas enciclopédias sobre a história da humanidade. Alguns livros que ressaltam a sensualidade feminina sugerem certo interesse sobre o assunto, livros sobre as mais diversas expressões da arte demonstraram seu gosto e admiração, fosse pela música, por artes plásticas, e outras manifestações artísticas, com destaque especial para o 
cinema, pois colecionou também mais de 2.000 DVDs, onde os clássicos mais importantes da sétima arte estão presentes.

O ex-libris impresso foi a marca de propriedade escolhida por Salete Maccalóz para registrar seus livros. Elaborado por uma de suas irmãs, que é artista plástica, como um bom ex-libris, ele sintetiza o seu interesse bibliofílico, pois juntamente à algumas áreas do Direito, a palavra Cultura também recebe destaque.

Figura 1. Ex-Libris da Desembargadora Federal Salete Maccalóz

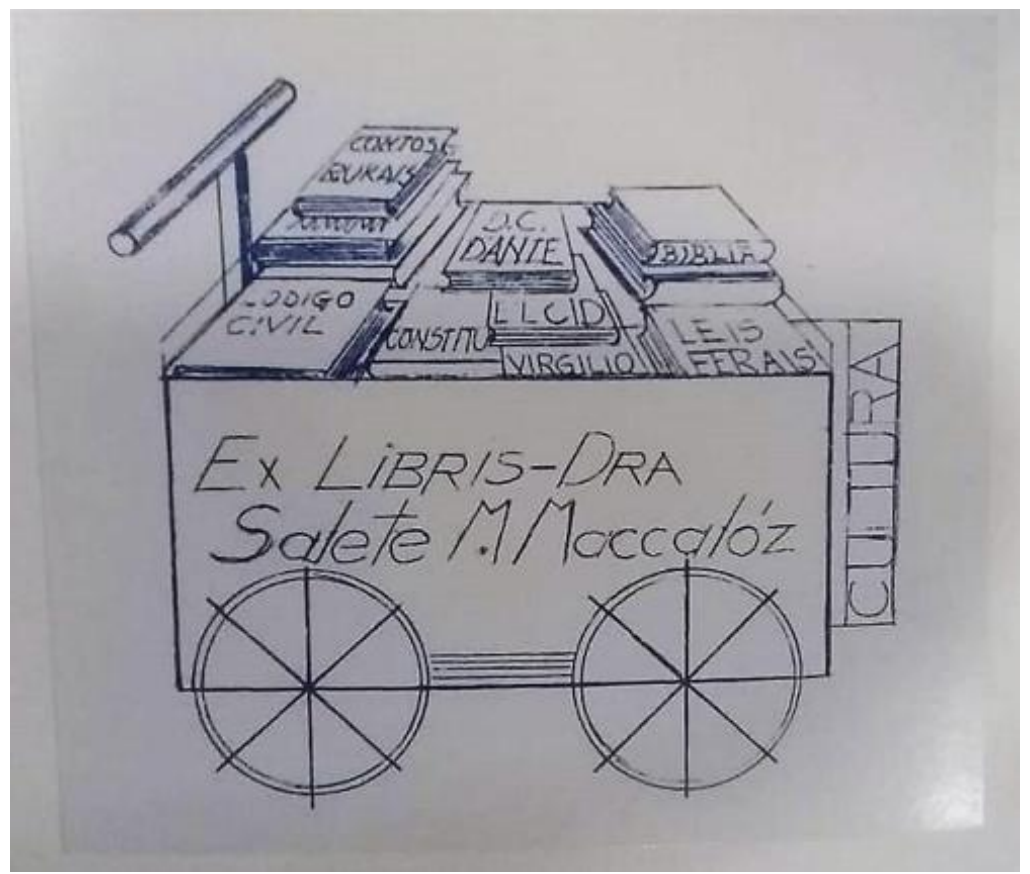

Fonte: Acervo da Biblioteca CCJF (2018)

Ao atribuir à Salete Maccalóz a qualidade de uma mulher bibliófila, o fazemos não só pelos traços e particularidades reveladas em teorias que tratam sobre o assunto. $\mathrm{O}$ contato com acervos bibliográficos particulares, permite de forma natural, a percepção sobre as características do colecionador, porém o que chama mais atenção é o fato deste atributo ser outorgado a uma "mulher", sim, pois as mulheres antes só eram tratadas como 
meras colecionadoras de futilidades, ou até mesmo, quando casadas com bibliófilos, eram consideradas muitas vezes como inimigas das bibliotecas dos maridos. Ao mudar esse olhar, consegue-se inverter tais percepções e, a despeito de opiniões preconceituosas, demonstrar os detalhes da bibliófila Salete Maccalóz, que manteve sua potência e firmeza, sem que para isso fosse preciso perder sua sensibilidade, emoção, coragem e, principalmente, a sua audácia.

Para modificarmos este panorama é necessário corrigir falhas e desfazer ideias retrógradas e diminutas em relação às mulheres que se atrevem a adentrar nos universos antes exclusivamente masculinos.

Pode-se evidenciar o protagonismo na qualidade dessas colecionadoras ao dizer que mulheres assim representam posturas importantes dentro da sociedade, pois sugerem um equilíbrio mais justo dentro do universo do colecionismo bibliográfico. Colocam em destaque, não o fato de ser homem ou mulher, mas a importância de contribuir positivamente e de forma efetiva para a construção de uma sociedade munida de valores culturais, que trate seus componentes como iguais, que constate o valor de cada indivíduo por suas ações, mas sobretudo que reconheça que é necessário evidenciar e focalizar nossos olhares naquelas que antes viviam apagadas na história das bibliotecas, as mulheres colecionadoras, as bibliófilas, mulheres como Salete Maccalóz e Maria Annunciada Chaves. 


\section{CONCLUSÕES}

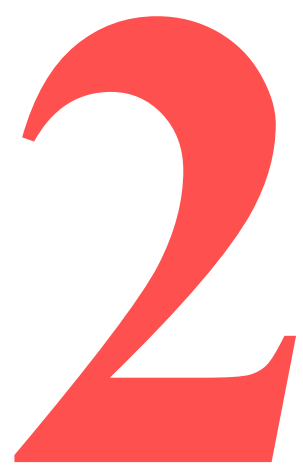

Nossa intenção com este artigo foi apresentar e dar a conhecer traços das trajetórias de duas bibliófilas brasileiras, e com isso, propor uma discussão em torno dos termos bibliófila, biblioteca de mulher e biblioteca particular pessoal de mulheres. Para isso, com uso da seleção de alguns autores dos séculos XIX e XX, ressaltar algumas marcas discursivas sobre a relação mulher e biblioteca e deixar a questão de até que ponto ainda não estão presentes em nossa memória coletiva e discursiva.

Sobre a relação leitor-livro-leitura, Darnton (1992: 203) afirmou que: “[os historiadores do livro] tendo estudado a leitura como um fenômeno social, podem responder muitas perguntas de "quem", "o que", "onde" e "quando". Tania Bessone no comentário que faz sobre essa ideia considerou que no estudo das bibliotecas particulares pessoais é possível estabelecer essa dinâmica.

Por considerar que "uma biblioteca não é simplesmente o somatório de livros" (Bessone, 1999: 22) e a trajetória dos seus proprietários, acreditamos que há ainda um elemento simbólico que não pode deixar de ser considerado frente a esses objetos que representam patrimônio bibliográfico, qual seja, por aqueles livros e naqueles livros a memória do antigo dono se prolonga 
(Azevedo, 2010). De alguma maneira, essa memória, ou muito mais, essa essência está ali, naqueles livros que, às vezes, ao olharmos para eles dão a falsa de ideia de silentes, discretos e passivos, quando na verdade certos livros naquele conjunto podem ter sido determinantes e basilares para as carreiras de seus donos. E também, no hobby, na parte que o dono colecionava por fruição, podem existir conjuntos documentais únicos pois foram amealhados ao longo de uma vida, como por exemplo, cardápios de jantares, cartões postais, revistas literárias ou não, etc.

Muito frequentemente, a biografia de uma biblioteca particular pessoal é entremeada de empacotar (Benjamim, 2000) e desempacotar (Manguel, 2001), porém, haverá um último movimento desses em que, na maioria dos casos, o proprietário não estará presente.

A relação do colecionador com seus livros pode ser visceral. Esses livros, amealhados ao longo de uma vida, foram testemunhas de inúmeros momentos daquela pessoa, são parte da memória de entes queridos, como no caso da biblioteca particular e pessoal, cuja início geralmente com livros herdados, como ocorreu com Annunciada Chaves.

Os livros são objetos e, como tais, podemos olhar a história das bibliotecas particulares pessoais sob essa ótica (Azevedo e Loureiro, 2019), pois dessa forma somos capazes de fazer uma reflexão acerca da história desses objetos na vida dessas pessoas (De Waal, 2011; Stallybras, 2016).

No filme La Dernière folie de Claire Darling (2018) a personagem interpretada por Catherine Deneuve exemplifica de maneira muito sensível que os objetos, sobretudo aqueles que passam por gerações, além de guardiões de memórias, são como entidades personificadas que convivem com a família, para o bem ou para o mal. Por isso, pode ser que para alguns 
seja tão doloroso se desfazer de alguns de seus livros, dependendo do tipo de memória que carrega.

Na literatura da história do livro e da leitura, observam-se alguns episódios em que colecionadores ficam com seus livros até os últimos momentos de suas vidas, não apenas pelo mero apego - como com ironia muitas vezes é visto. Há que lembrar ainda, no caso das duas bibliófilas, que são pessoas que fazem parte de uma geração livresca, ou seja, dependiam do livro para sua formação.

Suas bibliotecas além de formação, podem ter sido lugares de consolação (Blom, 2003), de apoio emocional, de refúgio (Schwarcz, 2017), um verdadeiro ente, uma companheira. Não são simplesmente, como pensam alguns, um depósito acumulativo de caprichos (Dunning, 2009). Ora, como dissemos anteriormente, se a biblioteca também era lugar de ofício, ela estará com o proprietário até o derradeiro momento, sobretudo se este morreu ainda no exercício profissional, como no caso de Maccalóz - e de tantos outros.

As bibliotecas de Maria Annunciada Ramos Chaves e Salete Maria Polita Maccalóz não foram meros exemplos para nossas reflexões, ao contrário, elas foram e continuarão a ser as forças motrizes que nos motivarão a seguir nessa investigação.

Por fim, ensejamos que pesquisas que versam sobre o assunto possam ser mais conhecidas, que outras surjam e até mesmo que se promovam eventos específicos para discutimos o tema, afinal: Bibliófilas, sim! E-por que não?! 
Assamann, Aleida (2011). Espaços da recordação: formas e transformações da memória cultural. São Paulo. Ed. da Unicamp.

Beckmann, Clodoaldo F. R. (2006). Homenagem à Maria Annunciada Chaves. Rev. Cult. do Pará, Belém , vol. 17 (2) 177-182, jul./dez.

Benjamim, Walter (2000). "Rua de mão única", in: Obras Escolhidas. São Paulo. Brasiliense. (pp. 227-235).

Bessone, Tania Maria (1997). Palácios de destinos cruzados: bibliotecas, homens e livros no Rio de Janeiro, 1870-1920. Rio de Janeiro: Arquivo Nacional.

Blom, Philip (2002). Ter e manter: uma coleção íntima de colecionadores e coleções. Rio de Janeiro. Record.

Campos, Fernanda Maria Guedes de (2015). Para se achar facilmente o que se busca: bibliotecas, catálogos e leitores no ambiente religioso (século XVIII). Lisboa: Caleidoscópio. 
Cândido, António (1990). “A evolução da cultura de um homem se evidencia nos livros que leu”. In: Notícia bibliográfica e história, Campinas, n. 135. (pp. 82-86).

Cim, Albert (1919). Les femmes et les livres. Paris: Ancienne Librairie Fontemoing.

Courcelles, Dominique de e Julián, Carmen val (réunis). (1999). Des femmes et des les livres: France et Espagnes, XIVe-XVIIe siècle: actes de la journée d'étude organisée par l'École nationale des chartes et l'École normale supérieure de Fontenay/Saint-Cloud (Paris, 30 avril 1998). Paris: École des Chartes.

Damaso, Daniele (1997). Annunciada: a história de um compromisso. Trabalho de Conclusão de Curso (Graduação em Comunicação Social) - Centro de Letras e Artes, Universidade Federal do Pará, Belém. Orientador: Lúcio Flávio Pinto.

Darnton, Robert (1992). "História da Leitura". In: Burker, Peter (Org.) A Escrita da história: novas perspectivas. São Paulo. Ed. UNESP, (pp. 199-236).

Diaconoff, Suellen (2005). Through the reading glass: women, books, and sex in the French Enlightenment. New York. State University of New York Press.

Dunning, John (2009). O Último caso da colecionadora de livros. São Paulo. Companhia das Letras.

Gelber, Steven M (1999). Hobbies: leisure and the culture of work in America. New York. Columbia University Press.

Haight, Anne Lyon (1937). Are women the natural enemies of books? In: Rogers, Bruce; Stein, Gertrude e Wakefield, Lucina Smith. Bookmaking on the Distaff Side. New York. The Distaff Side.

Holborn, Guy (2006). Lawyers and their libraries. In: Black, A. and Hoare, P. (eds.), The Cambridge history of libraries in Britain and Ireland. Cambridge, v. 3 (1850-2000), p. 453-469.

Labouchere, Norma (1895). Ladies'Book-plates: an illustrated handbook for Collectors and Book-lovers. London. George Bell \& Sons.

Moraes, Rubens Borba de. (1976) O Bibliófilo aprendiz. São Paulo. Companhia Editora Nacional.

Namer, Gérard (1987). Memoire et societé. Paris. Méridien. 
Pearson, David. Provenance research in book history: a handbook. London. The British Library, 2019.

Quentin-Bauchart, Ernest (1886). Les Femmes bibliophiles de France (XVIe, XVIIe, \& XVIIIe siècles). Paris. Damascène Morgand, libraire.

Rêgo, Clóvis Moraes (2002). Curriculum vitae da Professora Doutora Maria Annunciada Ramos Chaves. In: Subsídios para a história do Colégio Estadual 'Paes de Carvalho'. Belém. Ed. da UFPA, p. 145-162. (Memórias especiais, 1).

Roberts, W (1895). The book-hunter in London: historical and other studies of collectors and collecting. London. Elliot Stock.

Sarges, Maria de Nazaré dos Santos. Discurso de posse no Instituto Histórico e Geográfico do Pará. Belém, 2016. 13 p.

Schwarcz, Lilia Moritz (2017). Lima Barreto: triste visionário. São Paulo. Companhia das Letras.

Sontag, S. (2012). As Consciousness Is Harnessed to Flesh: Journals and Notebooks, 1964-1980. New York. Farrar, Straus and Giroux.

Stallybrass, Peter (2016). O Casaco de Marx: roupa, memória, dor. 5.ed. rev. Belo Horizonte. Autêntica.

Wall, Edmund de (2011). A Lebre com olhos de âmbar. Rio de Janeiro. Intrínseca.

Zaid, Gabriel (2004). Livros Demais!: sobre ler, escrever e publicar. São Paulo. Summus.

\section{Webgrafia}

Araújo, Adelma Ferreira de (2017). Rubens Borba de Moraes e José Mindlin: bibliofilia como patrimônio informacional. 110 f. Dissertação (Mestrado em Ciência da Informação) - Programa de Pós-Graduação em Ciência da Informação, Centro de Artes e Comunicação, Universidade Federal de Pernambuco, Recife, 2017. (Disponível em: https://repositorio.ufpe.br/handle/123456789/25239. Acesso em: 27.03.2020) 
Azevedo, F. C. (2010). “A doação da biblioteca João do Rio ao Real Gabinete Português de Leitura: aspectos de uma história pouco conhecida". Perspectivas em Ciência da Informação, vol 15(3): 233-249, nov. ISSN 19815344, 2010 (Disponível em: http://portaldeperiodicos.eci.ufmg.br/index.php/pci/article/view/1070. Acesso em: $\underline{11.03 .2020)}$

Azevedo, F. C. \& Loureiro, M. L. N. M. (2019). Afinal, os objetos falam? reflexões sobre objetos, coleções e memória. In: XX Encontro Nacional de Pesquisa em Ciência da Informação - $\quad$ ENANCIB. https://conferencias.ufsc.br/index.php/enancib/2019/paper/view/951. Acesso em: 27.03.2020).

Azevedo, Fabiano Cataldo de e Cavalcante, Stefanie Freire (2018). Conde de Azevedo e Camilo Castelo Branco: quando a epistolografia revela afetos e a formação de uma biblioteca. In: XVIII Encontro de História: Encontro Internacional: História \& Pareceria. ST. 45. Livros, bibliotecas, cartas e outros escritos: a apropriações, 23 a 27 de julho de $2018 . \quad 23$ slides. (Disponível em: https://www.academia.edu/37118232/Conde_de_Azevedo_e_Camilo_Castelo_Branco quando_a_epistolografia_revela_afetos_e_a_forma\%C3\%A7\%C3\%A3o_de_uma_bibli oteca. Acesso em: 27.03.2020).

Brasil. Justiça Federal. Tribunal Federal 2a Região (2017). Jus Brasil notícias. Exposição in memoriam de Desembargadores do TRF2. (Disponível em: http://www10.trf2.jus.br/institucional/magistrados/desembargadora-federal-saletemaccalozl. Acesso em: 10 abr. 2020).

Bury, R. (1889). The Philobiblon of Richard de Bury. New York: Lockwood and Coombes. (Disponível em: http://www.gutenberg.org/ebooks/626. Acesso em: 15.03.2020)

Fisher, Amália E. (2017), coordenadora geral do Fundo ELAS. Informações verbais. In: ELAS: Fundo de Investimento Social. Nota de pesar. (Disponível em: http://www.fundosocialelas.org/noticias-conteudo.asp?cod=361. Acesso em: 29.03.2020).

Freire, Anselmo Braamcamp (1921). Introdução. In: Santos, José dos (red.). Catálogo da importante e preciosíssima livraria, que pertenceu aos notáveis escritores e bibliófilos Condes de Azevedo e de Samodães. Porto: Tip. da Empresa Literária e Tipográfica. 
(Disponível em: https://archive.org/details/catlogodaimpor01azevuoft. Acesso em: 04.04.2020).

FREIRE, Stefanie Cavalcanti. Dedicatórias manuscritas: relações de afeto e sociabilidade na biblioteca Manuel Bandeira. 2013. 406 f. Dissertação (Mestrado em História) - Universidade Federal do Estado do Rio de Janeiro, Rio de Janeiro, 2013. (Disponível em: http://www.repositorio-bc.unirio.br:8080/xmlui/handle/unirio/12139. Acesso em: 04.04.2020).

Jaramillo, Orlanda; Marín-Agudelo, Sebastián-Alejandro. Patrimonio bibliográfico enla biblioteca pública: memorias locales e identidades nacionales. El Profesional de la Información, vol. 23(4): 425-432. 2014, (Disponível em: https://recyt.fecyt.es/index.php/EPI/article/view/epi.2014.jul.11/16972. Acessado em $\underline{20.03 .2020)}$

La dernière folie de Claire Darling (2018). (Disponível em: https://www.imdb.com/title/tt6961808/. Acessado em: 01.04.2020)

Maciel, Francisca Izabel Pereira (2001). Lúcia Casasanta e o método global de contos: uma contribuição à história da alfabetização em Minas Gerais. 153 f. Tese (Doutorado em Educação) - Programa de Pós-Graduação em Educação, Faculdade de Educação, Universidade Federal de Minas Gerais, Belo Horizonte, 2001. (Disponível em: https://repositorio.ufmg.br/handle/1843/FAEC-86PRY6. Acesso em: 14.04.2020).

Manguel, Alberto (2011). Embalando a minha biblioteca. Lisboa. Tinta-da-China.

Melo, Kelly Castelo Branco da Silva (2011). Bibliofilia: um tipo de colecionismo, um caminho de coleção e memória. 49 f. TCC (Graduação) - Curso de Biblioteconomia, Universidade Federal do Estado do Rio de Janeiro. Rio de Janeiro, 2011. (Disponível em: http://www.memoriasocial.pro.br/documentos/Dissertações/Diss356.pdf. Acesso em: 27 abr. 2020).

Melo, Kelly Castelo Branco da Silva (2018). Coleção e melancolia: universos mneumônicos-patrimoniais. 145 f. Tese (Doutorado) - Curso de Memória Social, Universidade Federal do Estado do Rio de Janeiro, Rio de Janeiro, 2018. (Disponível em: http://www.repositorio-bc.unirio.br:8080/xmlui/handle/unirio/12831 Acesso em: 27 abr. 2020). 
Memorial do Livro Moronguêtá (2020). Acervos: Maria Annunciada Ramos Chaves. (Disponível em https://core.ac.uk/download/pdf/38822662.pdf acessado em: 28.03.2020)

Palma Peña, Juan Miguel (2011). "La socialización del patrimonio bibliográfico y documental de la humanidad desde la perpectiva de los derechos culturales". Revista General de Información y Documentación, Vol. 21: 291-312. (Disponível em https://core.ac.uk/download/pdf/38822662.pdf acessado em: 08.04.2020)

Palma Peña, Juan Miguel (2013). El patrimonio cultural, bibliográfico y documental de la humanidad: revisiones conceptuales, legislativas e informativas para una educación sobre patrimonio. Cuicuilco, México, Vol. 20 (58): 31-58, sep./dic. (Disponível em http://www.scielo.org.mx/scielo.php?script=sci_arttext\&pid=S0185$\underline{16592013000300003}$ acessado em: 11.04.2020)

Reifschneider, Oto Dias Becker (2011). A Bibliofilia no Brasil. 303 f., il. Tese (Doutorado em Ciência da Informação) - Universidade de Brasília, Brasília. (Disponível em: https://repositorio.unb.br/handle/10482/10744. Acesso em: 02.04.2020).

Roberts, W (1895). The book-hunter in London: historical and other studies of collectors and collecting. London. Elliot Stock.

Sousa, Moizeis Sobreira de (2017). Dos livros de devoção ao romance: a numerosa e escolhida biblioteca da Princesa do Brasil, D. Maria Francisca Benedita (1746-1829). História, São Paulo, n. 36, (Disponível em: https://www.scielo.br/scielo.php?pid=S010190742017000100405\&script=sci_arttext. Acesso em: 29.03.2020). 